\title{
Inhaltsverzeichnis
}

\author{
Clemens JABLONER
}

Die Gerichtshöfe des öffentlichen Rechts im Zuge des Staatsumbaues 1918 bis 1920 ........

Christian NESCHWARA, Nicolas WIMBERGER

Keck versus Wepp:

Ein Erb- und Ehegutsprozess in Wien zu Beginn der Rezeptionszeit

Thomas OLECHOWSKI

Die behördliche Einstellung der „Pädagogischen Blätter“ 1936.

Schulpolitik, Presserecht und Verwaltungsgerichtsbarkeit in der Zeit

des Autoritären Ständestaates

\section{Jana OSTERKAMP}

Verfassungshüter ohne politischen Rückhalt.

Das tschechoslowakische Verfassungsgericht nach 1920 im Vergleich mit Österreich .....

Ilse REITER-ZATLOUKAL

Staatsbürgerschaftsrecht in Österreich 1933-1938

Christoph SCHMETTERER

Das letztwilligen Verfügungen Kaiser Franz Josephs

Kamila STAUDIGL-CIECHOWICZ

„...dass die Facultätsstudien Staatsdiener, nicht Gelehrte heranzubilden haben...“

Zur Einführung der juristischen Staatsprüfung $1850 .$.

Ewald WIEDERIN

Die verfassungspolitische Diskussion über die Einrichtung Österreichs als Bundesstaat 
